\title{
Peacebuilding through Language Mentorship in Rwanda's Primary Education: Challenges facing key stakeholders https://dx.doi.org/10.4314/rj.v2i2.5A
}

Jean de Dieu NKUBITO, Center for Language Enhancement, College of Arts and Social Sciences, University of Rwanda, email : nkubidos@gmail.com

Anastasie UWABABYEYI, University of Tourism, Technology and Business Studies, email: uwanastasie@yahoo.fr

\begin{abstract}
Several studies have been conducted following a 2008 policy in Rwanda that made English language the medium of instruction from the fourth year of primary school. However, there is a considerable research gap between language policy changes, positive peace and peacebuilding generally. Thus, based on existing knowledge that language introduction can harm positive peace, this paper investigates how a language mentorship programme can mitigate teachers' worries in their working environment and therefore play a role in positive peace restoration. Qualitative data were collected from mentors, head teachers, and teachers sampled from four rural districts in Rwanda. The findings indicate that the School-Based Mentorship (SBM) programme contributes to positive peace restoration whenever mentors are adequately helping teachers to recover their confidence in classroom management. SBM is expected to help teachers feel comfortable in the language of instruction, which makes them feel safe at work and they subsequently regain the classroom authority they had been lacking. SBM yields positive results where the mentor and head teacher work hand in hand. Thus, lack of such collaboration, a single class for all trainees despite their different language needs, lack of adequate teaching materials, unstructured or absence of mentors' regular monitoring and evaluation, are among challenges that hinder the optimum delivery of the programme.
\end{abstract}

Key words: Mentorship programme, English as a medium of instruction, language policy, peacebuilding, positive peace, mentors, teachers.

\section{Introduction}

Rwanda is a country that was severely shaken by the 1994 genocide against the Tutsi. Over the last two decades, however, the country has made tremendous steps to rebuild its torn social fabric. The vitality of the country is observed through its economic growth (Pinon and Haydon, 2010) as well as successful mechanisms and strategies to increase the citizens' social wellbeing. The education sector has not been left behind as it also underwent considerable changes, and some of them are related to the language of instruction in the country. 
In 1995, the Government of Rwanda (GoR) introduced English as an official language and a medium of instruction in addition to Kinyarwanda and French (Kagwesage, 2013; LeClerc, 2008; Samuelson \& Freedman, 2010). The new status of English was influenced by a new demographic composition of the Rwandan society (Kagwesage, 2013) that included people who grew up in English speaking countries who did not speak French (Samuelson and Freedman, 2010).

In 2008, the government made a major language shift in the education system. Thus, a new policy was hastily set up requiring teachers and learners, from primary four to tertiary level, to use English as the medium of instruction for all academic disciplines (MINEDUC, 2008). This new language policy concerned all learners regardless of whether they had been learning in French or in English until that point. The country's social dynamics, the search for national unity and integration in the Rwandan society, as well as prioritising economic motivations were the major reasons to opt for English as the only medium of instruction (Samuelson and Freedman, 2010). Thus, the change in the language of instruction aimed at enabling people to integrate more easily into regional organisations such as the East African Community (EAC), and widen their access to international markets (MINEDUC, 2008).

However, the implementation of the language shift in Rwanda led to some teachers' discomfort, especially in primary schools (Uwambayinema, 2013; Adedeji \& Olaniyan, 2011; Clover, 2012; Rosendal, 2009; Le Clerc, 2008 in Steflja, 2012; Samuelson and Freedman, 2010), as most of them were initially francophone. The embarrassment resulting from the introduction of English as a new language of instruction is explained as a threat to positive peace (Barash and Webel, 2002). This concept is generally defined as an overarching framework that creates an optimal environment for human potential to flourish, promotes fair social conditions, reduces grievances and resolves remaining disagreements without the use of violence (Institute for Economics and Peace, 2015; Barash and Webel, 2002).

Thus, the emerging situation brought about a need for peace-building, not in the wider perspective of the Rwandan society, but peace-building in a narrow dimension, i.e. limited to the teaching sector, so as to safeguard the threatened positive peace in that area. In fact, the change in the language policy affected teachers' positive peace as some of them felt that their career was being jeopardised (Lulu, 2011, Clover, 2012).

Although many studies have been conducted on English as a medium of instruction to the detriment of French in Rwanda (Nzitabakuze, 2011; Uwambayinema, 2013, Kagwesage, 2013; Sinclair, 2012; Assan and Walker, 2012; etc.), there is a substantial research gap between the above-mentioned language policy change and peacebuilding. As per the 
empirical literature in our disposal, there has been no explicit research to study the impact of language policy changes on positive peace and peacebuilding at large. A change in language policy may jeopardize positive peace in the teaching sector, as indicated above, since teachers who are not familiar with the new language may fail to communicate in their classes through the new language of instruction. This was thought to result in job insecurity, guilty consciousness for not delivering as they should, as well as latent fear to lose their jobs if the lack of proficiency in the new language of instruction persisted. In fact, Samuelson and Freedman (2010) indicate that language policies are one of the factors that can cause conflict and there is a close relationship between language and identity, between language and political, societal, and economic conflicts in a society that undergoes changes in language use. In the Rwandan context, the change in language policy needs analysing to learn more on the impact of the introduction of English as a sole medium of instruction, from the fourth year of primary school, on teachers' ability to communicate and interrelate among themselves in their working environment and more particularly, between teachers and their leaders, as well as between teachers and pupils.

Thus, the point of departure for this study is the research gap in studying attempts to restore teachers' positive peace and their comfort vis-à-vis English as a medium of instruction. Teachers are trusted in society since they deliver knowledge to young people as future leaders and parents. Moreover, teachers are key determinants of education quality (Mourshed et al. Sayed et al. in Sayed et. al., 2016) and they therefore play a paramount role as agents of nation building, identity construction and peace and reconciliation (Durrani and Dunne, 2010; Smith et al. in Sayed et al., 2016). Consequently, promoting positive peace within the teachers' working environment will end up positively affecting the whole nation.

The study aims at eliciting one of the ways in which the above mentioned research gap is being bridged by exploring how the school-based mentorship (SBM) programme contributes to positive peace restoration. This programme was established by MINEDUC in 2012 and it was expected to support teachers in developing their English language skills as well as improving teaching methods (REB, 2013; British Council, 2014).

The present study also brings to light the challenges faced by SBM's key actors in performing their duties, and provides some recommendations to mitigate the identified problems.

\section{Scope of the study}

Although the mentorship programme operates at both primary and secondary school levels in 12-year basic education, the study was only limited to the primary schools in rural areas. The delimitation was motivated mainly by the fact that English language 
problems are more reported in rural primary schools (Uwambayinema, 2013; Nzitabakuze, 2011) than anywhere else. In addition, from our initial observation, the secondary school framework of 12-year basic education comprises many young teachers who may have studied English either at secondary school or university; hence we assumed that they do not face acute challenges relating to English language.

The study was guided by the following research questions:

1. How do teachers of different ages interpret SBM as a tool to promote positive peace?

2. Do mentors, both local and regional, use the programme as a peace-promoting tool that helps teachers restore positive peace through the English Language?

3. What are the challenges faced by key actors in the SBM and how can they be addressed?

\section{Theoretical Framework}

The study falls within a socio-linguistic approach and is inscribed in the broad spectrum of studying the impact of language policy changes on positive peace and peacebuilding. In fact, this study is guided by the theory that an abrupt change in language policy/ language function may lead to conflict as particular identities and sections of society are linked to the new functional language more than others in a society (Friedrich, 2007; Phillipson, 1992). In the context of Rwanda, two groups emerged resulting from the implementation of a new language policy that made English a medium of instruction to replace French in a major portion of the education sector. On the one hand, there are teachers who had studied in a French-speaking environment and they were subsequently teaching in French since the latter was also a medium of instruction. On the other hand, there are some others who had studied in English either because they had grown up outside Rwanda in an English-speaking environment or simply because English was a major in their studies. Thus, with the new language policy implementation, non-English speaking teachers felt disadvantaged compared to English-speaking group (Steflija, 2012).

The resulting dynamic therefore tended to compromise positive peace in terms of the existing working environment in Rwanda. Positive peace is defined as the establishment of egalitarian working conditions and lack of any structure that can bring about people's resentment and fear for their bread-winning occupations (Galtung, 1969). With this definition, the author indicates that there is no overt conflict among citizens, but there are latent grievances and dissatisfaction that could explode into open social conflict if given opportunity to be manifested. Thus, respect for human rights, fair working conditions, 
and economic wellbeing need to be constantly in place as necessary ingredients for the maintenance of peace, and anything likely to disturb them could bring harm to 'positive peace' and 'peacebuilding' as indicated Barash and Webel(2002).

The introduction of English as a sole medium of instruction from primary four faced some bottlenecks. One of them was its interpretation by some Francophone teachers who believed that they were going to lose their jobs to foreigners who were flocking to the country in big numbers to teach English (Clover, 2012). As a result, the socio-linguistic theory according to which universal languages can do more harm than good (Friedrich, 2007) started being manifest. In fact, English as a universal language is allegedly criticised for displacing other languages (Phillipson, 1992), and promoting communicative inequality (Tsuda, 1997). This study therefore links education, through language policy, with peacebuilding, thereby examining the role of the mentorship programme to overcome any positive peace obstacles inherent to the introduction of the new language of instruction.

\section{Methodology}

A qualitative exploratory study was carried out in four rural districts of Rwanda namely Nyaruguru, Bugesera, Rulindo and Rutsiro, i.e. one district per province was selected except for Kigali City. Two mentored schools were selected from each district to provide the main informants from the research population composed of teachers, mentors, and head teachers. Selected districts and schools were sampled using a multi-stage random sampling technique.

In addition, one mentor and one head-teacher from the eight sampled schools were purposively selected through convenience sampling. Hence, eight mentors and eight head-teachers, each one per school, participated in the study as informants.

Moreover, forty teachers were purposively selected, and judgment sampling was used to select five teachers per school. Teaching experience was taken into account for informants to be selected, including the selection of teachers who were on duty even before English was made the only medium of instruction from primary four.

Regarding data collection, semi-structured interviews were administered to all informants, and focus group discussions were conducted with teachers so as to crosscheck the obtained information. Two class observations were also done with two different teachers per school. The class observation allowed to collect some information on the extent to which SBM was implemented, on the class atmosphere in general, as well as the attitude and behavior of the teachers while using English. 


\section{Findings}

In this study, the findings are from the respondents' narratives on SBM itself and how the latter affects teachers' perceptions towards the use of English language. The research findings also shed light on the link between SBM and positive peace in the Rwandan education sector.

\section{Negative effect of Rwanda's new language policy implementation on teaching environment}

The research analysed the teachers' responses when they learnt about the policy that made English the sole language of instruction from the fourth year of primary school to the detriment of French. Such information was collected to check whether the teachers were apprehensive of the new language of instruction. In addition, the information was meant to prove whether the new language was not compromising their job security and teachers' positive peace in their working environment.

\section{Teachers' narratives on their attitudes prior to mentorship implementation}

Teachers provided various testimonies describing their attitudes when they learnt that English was going to be used as a medium of instruction. Their narratives revealed the following conditions: discomfort, despondency, fear of losing their jobs, and overall challenging situation as depicted in the statement below:

It was challenging for me as I had been teaching in Kinyarwanda and French only. I had not studied English sufficiently to be able to teach in that language. I was therefore so worried that I could even lose my job and I think I was not the only one with such concerns. I thought that if I fail to teach in English I would subsequently be sacked from my job and get back home.

It is worth noting that the discomfort and fear to lose the job was more experienced by teachers who are advanced in age as argued one of the informants:

Regarding my colleagues, as you understand, I was working with older colleagues who were in a worse situation, since many of them were going to face English for the first time. They $[\ldots]$ were very desperate as they were saying that their advanced age will not allow learning that language. Old teachers thought they were going to be sacked and replaced by new competent teachers who could easily use English in class.

Although the arrival of English was considered a problem, a few teachers among the respondents found the introduction of the new language of instruction differently as in the 
following testimony: 'I had no fear; many teachers' level in English was almost the same. So I believed that the government would find a solution to the problem and it has been so'.

Thus, all teachers did not have the same perception of English as a medium of instruction, and the divergence was mainly due to their age and the study background since there are some who had studied English, especially young teachers, while others had not.

\section{Head teachers' perceptions of English as a medium of instruction}

Giving their views on the use of English as a medium of instruction, 7 out of 8 interviewed head teachers recognised that they were worried, not necessarily for themselves but mainly for their teachers.

According to one head teacher, it was a big problem for teachers to start using English as the new language of instruction immediately after the adoption of the new language policy. This informant went on to indicate that, even herself, she had no hope, to keep her job as she was informed that English was to replace French as a language of instruction:

I felt like the job for teachers who studied in the francophone system was terminating. I thought we were going to be dismissed and that the job would be taken by teachers who have studied in English. Then, we were surprised when they told us that we will keep working and be given on-job English language training, until we get the ability to teach in that language.

The above described atmosphere was also emphasised by another head teacher who indicated that the worry and fear were inevitable as he thought that the introduction of English was going to be a hard task to leaders and francophone teachers without an English speaking background. This head teacher feared that some teachers' job could be at stake, but finally nobody left the job because of that reason.

\section{Contribution of SBM to peacebuilding}

The analysis of the informants' narratives indicated that a smooth collaboration among mentors, teachers and head teachers could help mentees get out of the initial confusion, and feel at ease with the English language. Such collaboration could help teachers to settle down and comfortably carry out their duties.

In their narratives, all mentors indicated that they aim at helping teachers get at ease with the target language by developing their communication skills. The latter end up reviving teachers' self-confidence and make them fully integrated in their working environment. 
Thus, mitigating teachers' grievances would help them gain positive peace as conceived by the Institute of Economics and Peace (2015) and Galtung (1969). In actual fact, teachers would not feel any more resentment once they are comfortable with using English in their career as reiterated one of the mentors:

I think with peacebuilding you don't mean the lack of bullets or war, but that kind of positive atmosphere [in which] there is no tension and pressure. You can carry out your duties peacefully without any problem. It is in that context that we help teachers; first of all, to make them feel comfortable. In addition, to live in peace with the language because there was initially that kind of conflict: conflict between the teachers, who are the key actors in the mentorship programme, and the new language which was coming.

Regarding the description of the benefits from SBM, different teachers highlighted the importance of the programme in achieving positive peace. The teachers acknowledged that the kind of fear they had, before the arrival of mentors, was fading away owing to the mentors' support in using English. The teachers also added that, unlike before, when they are visited by Rwanda Education Board (REB) officials, they are no longer afraid since they have acquired some English speaking skills. They are therefore able to run their classes independently owing to the mentorship programme.

However, even though the majority of teachers affirmed to have gained a lot from SBM, there were some others who indicated that a lot needed to be done. According to them, SBM can lead to positive peace when English knowledge increases and teachers feel free to speak English, which has not been fully achieved. This corroborates what we observed in classes as we realised that some teachers were unable to deliver their message in correct English and had to resort to Kinyarwanda, their mother tongue. Thus, teachers reiterated that mentors must work hard in order to help trainees according to their levels.

During group discussions, a few teachers also mentioned that they considered their mentors irresponsible as the latter sometimes disappeared before time or stayed at home. Commenting on the point raised, another teacher added 'If I get a good mentor, I can feel peaceful. I even today teach in Kinyarwanda most of the time. If I knew English and were able to teach in this language, I could feel peaceful as this would provide job security for me, but I'm not happy today given that I can't deliver as I wish.'

In short, teachers from all the schools under investigation indicated that the mentors' contribution to peace building resides in upgrading teachers' level of proficiency in English. Positive peace will therefore be fully attained if teachers gain their selfconfidence in carrying out their duties. The end result would not only be the teachers' inner peace and comfort with the English language, but also improvement in the 
provision of quality education, which would positively impact the entire Rwandan community.

\section{Influence of mentors' origin on SBM contribution to peacebuilding}

School-based mentors included regional and local ones. In this regard, out of eight target schools, three of them were assisted by foreign mentors, and the remaining five by local mentors. The study therefore attempted to know if the origin of the mentors affects their contribution to peacebuilding. Thus, to achieve this aim, we analysed some narratives from teachers and head teachers, describing how they work and collaborate with mentors.

The majority of the informants indicated that they benefitted more from local mentors than foreign mentors as the latter were said to ignore teachers' accurate level of proficiency in English. They rather focus on advanced skills which makes it difficult for teachers to follow:

Based on the time spent with both mentors, I have realised that local mentors are more effective in terms of helping teachers familiarise with the English language. Foreigners seem to be superficial and focus on a few advanced skills, instead of starting from basic skills that can be considered to be a starting point to embark upon more advanced skills.

From the informants' narratives about the mentors' performance, we noted a striking pattern. We realised that, on the one hand, foreign mentors were more appreciated by younger teachers who, most of the time, had more advanced English language skills compared to senior teachers. On the other hand, Rwandan mentors were more praised by elder teachers because they often communicated in Kinyarwanda to understand one another. This implies that all trainees' aspirations were not catered for where all school teachers were trained by a single individual in the same classroom while their language needs were different. Thus, there may have been some teachers who, despite having undergone the mentorship programme, were not adequately helped to get the expected comfort with the English language. This situation may be a threat to positive peace on their side given that they cannot comfortably run their classes; hence they may still feel frustrated and think they are doing a risky job.

\section{Challenges faced by the mentorship programme and solutions towards peacebuilding}

The informants' narratives revealed that the mentorship programme faced a number of challenges such as the teachers' heavy workload among other things. According to the majority of informants, the teachers' heavy workload does not allow any spare time to attend the collective face-to-face training session with the mentors happening twice a 
week. The following assertion illustrates how teachers lacked adequate time to get trained which resulted in a negative outcome:

The programme is poorly conducted since there is no fixed timetable indicating the time the mentor will be with teachers. The latter are actually busy with their classes anytime they are at school. As a result, the mentor may arrive here and doesn't find any teacher to talk to given that everyone will be teaching.

Thus, due to an overloaded timetable, head teachers tried their best to arrange for the requested two hours devoted to language training. However, this sometimes created conflict between the head teacher and other teachers, when the latter were required to attend training after class while they were exhausted after long teaching hours. In addition, that arrangement to find room for the training was also reported to be the origin of conflict between the mentor and the head teacher. Indeed, some stubborn head teachers refused to provide the two hours for the training. The informants reported that the head teacher's excuse is sometimes that the training appears nowhere on the weekly teaching timetable. Hence mentors have to look for extra hours either over the weekend or on any of the weekdays after work, which is often difficult for teachers to attend.

Additional challenges that obstructed the maximum gain for the mentorship program beneficiaries include mixing all trainees in a single classroom despite their different English language needs, conflicting responsibilities between the mentors and head teachers, inadequate teaching and learning facilities, and the fact that each mentor had to take care of two schools.

\section{Discussion}

The study on SBM's input to peacebuilding attempts to establish a link between English language mentoring and peacebuilding in the education sector which has grossly been overlooked in previous studies. The discussion of the findings is mainly based on teachers' experience amid the language of instruction dynamics, and it is done through two dimensions. First, it is centered on a positive peace gap resulting from sudden language policy implementation in Rwanda. Then, the discussion scrutinises the mentorship programme interpreted as a tool for positive peace restoration in the teaching environment.

\section{Language policy implementation and positive peace}

The link between the English language and peacebuilding is based on the abruptness of the new language policy that made English the medium of instruction from primary four in Rwanda since 2008. This development has therefore posed some problems as many 
teachers have struggled to cope with their duties due to poor proficiency in the new medium of instruction (Le Clerc, 2008 in Steflja, 2012).

In expressing their grievances, the informant teachers and head teachers do not contradict the above cited writers. They rather indicate that all stakeholders should have been better prepared to use English as a medium of instruction. According to the respondents, English already existed as a subject at all levels of education, but the implementation of the new policy should have started with a transitional period. In the process, English as a subject could have been allotted more hours on the timetable. This would therefore allow teachers get more vocabulary and get conversant with English before using it as a medium of instruction.

Based on respondents' narrated experiences, we agree with Samuelson and Freedman (2010), Adedeji and Olaniyan (2011), Clover (2012), and Rosendal (2009) that the implementation of the new language policy was too abrupt. It was therefore inevitable for the implementers to face challenges that could directly affect their working styles and their daily teaching activities at large. Thus, as expressed by different informants, that situation brought about despair and a feeling of job insecurity for teachers, which is a threat to positive peace in their working environment.

The above described discomfort therefore supports the theory that universal languages, such as English, can result into tension which can be a threat to positive peace since they affect fair social conditions (Barash and Webel, 2002). Hence, based on the effect of universal language theory, we can argue that the abruptness of implementing the new language policy created a positive peace gap in Rwandan rural primary teaching environment that needed bridging.

\section{Mentorship programme as a tool to peacebuilding}

As confirmed in the respondents' narratives, the teachers' communication skills in English language were not enough to adequately engage in usual teaching activities. This affected their inner peace and self-confidence. There was therefore a need to fill the gap and re-establish appropriate conditions for teachers to smoothly conduct their classroom activities. In this regard, SBM was established as a solution to teachers' English language problems.

The analysed teaching platform indicates that there are conflicting expectations, and conflicting interpretations of the mentorship programme. Here we argue that different perceptions of the mentorship programme result from the teachers' initial conflict with the English language manifested when the latter was made the medium of instruction from primary four in Rwanda. Such a conflict was stressed by the head teachers. They 
indicated that some teachers felt ashamed, for example, in case they failed to communicate in a language they were supposed to master as role models not only in class, but also in society at large. Thus, failure to be at ease with English made some teachers feel that their job was at risk, and they were loosing their trustworthiness in society in case nothing was done to improve their English language skills. This also matches with scholars' views on the negative effect of the introduction of a new language in society and the inevitable subsequent conflict that it causes (Phillipson, 1992; Muhlhausler, 1996; Tsuda, 1997).

However, despite diverging teachers' attitudes vis-à-vis the mentorship programme, many respondents indicated that SBM is helping teachers to get rid of worry, despair, and fear of job insecurity felt at the beginning of implementing the new language policy. Thus, it should be argued that wherever SBM is conducted properly, its outcomes are linked to positive peace and peacebuilding as some teachers with no background in English have been enabled to overcome negative feelings resulting from the hasty implementation of the new language of instruction.

\section{Conclusion and recommendations}

This study has investigated the challenges inherent to the introduction of English as a sole medium of instruction from primary four in Rwanda. The research has indicated that the implementation of the new language policy has impacted on the comfort of some teachers, hence calling for action to restore the endangered positive peace in teaching environment.

The study has also analysed the impact of SBM on positive peace among primary school teaching staff in Rwanda. In this regard, a big number of respondents found the establishment of the above mentioned programme as a contribution to positive peace and peacebuilding in general since it allayed teachers' worries in their working environment. The study has revealed, however, that a peaceful working atmosphere depends on the relationship that exists between key actors, as well as the mentors' capacity to help teachers develop their communication skills in English.

To conduct SBM smoothly and overcome the observed challenges, there should be an adjustment of the teaching timetable in primary schools so as to accommodate hours for teachers to have face-to-face training sessions. Further, modules of English should be prepared separately according to the teachers' proficiency levels in English and relevant materials should be provided. Additionally, teachers offering the same subjects should be trained together so as to enable them learn technical terms. 
This paper also provides some suggestions for more research. In this perspective, further studies should be conducted on SBM so as to know how it develops over time. They should examine if amendments to SBM have made a positive impact on the teachers' positive peace vis-à-vis English language as a medium of instruction. Given that our study was only limited to primary school level, more research should be conducted to explore the effect of the mentorship programme to mentees in secondary schools.

\section{References}

1. Adedeji, S. O., and Olaniyan, O. (2011) Improving the conditions of teachers and teaching in rural schools across African countries. Addis Ababa, Ethiopia: UNESCO.

2. Assan, J., and Walker, L. (2012) The Political Economy of Contemporary Education and the Challenges of Switching Formal Education to English in Rwanda. In Rwanda Fast Forward: Social, Economic, Military and Reconciliation Prospects, eds. Campioni and Noack. London: Palgrave Macmillan.

3. Barash, D. P. and Webel, C. P. (2002) Peace and Conflict Studies. Thousand Oaks, CA: Sage.

4. British Council, 2014. School-based Mentors Programme. Retrieved on 26 January, 2015 from: http://www.britishcouncil.rw/programmes/education/school-based-mentors.

5. Clover, J. (2012) "Jury out on language-switch trend." The Guardian [London]. 13 November 2012. Retrieved on 27 January, 2015, from: http://www.theguardian.com/education/2012/nov/13/rwanda-english-language-lessons.

6. Friedrich, P. (2007) English for peace: toward a framework of Peace Sociolinguistics. World Englishes, 1(26), pp. 72-83.

7. Galtung, J. (1969) Violence, Peace, and Peace Research. Oslo: International Peace Research.

8. Institute for Economics and Peace, (2015). Global Peace Index Report 2015: Measuring Peace, its causes, and its economic value. Retrieved on 27 January, 2016, from: http://economicsandpeace.org/wp-content/uploads/2015/06/Global-Peace-IndexReport-2015_0.pdf.

9. Juma, M.K. (2005) Peacebuilding in Africa: Local and regional capacities for securing peace, reconstruction and development. Amsterdam: Arena Africana. 
10. Kagwesage, A.M. (2013) Coping with Learning through a Foreign Language in Higher Education in Rwanda. Linköping Studies in Behavioural Science No. 173. Linköping: Linköping University

11. LeClerc, J. (2008) "Rwanda: L'aménagement linguistique." Retrieved on 24January, 2015 from: www.tlfq.ulaval.ca/axl/afrique/rwanda.htm.

12. Lulu, J. (2011) Rwanda: Shifting the country's education curriculum from French to English persists-with turbulence. The Independent. 14 October, 2011. Retrieved on 22 January, 2015, from: http://independent.co.ug/rwanda-ed/rwanda/4718-parler-anglais

13. MINEDUC. (2008) Education sector strategic plan 2008-2012. Kigali: Ministry of Education.

14. Muhlh"ausler, P. (1996) Linguistic Ecology: Language Change and Linguistic Imperialism in the Pacific Rim. London: Routledge.

15. Nzitabakuze, C. (2011) Implementation of the English medium policy in Rwandan primary schools: A case of Gasabo district, Rwanda (Unpublished master's thesis). Nairobi: Kenyetta University.

16. Phillipson, R. (1992) Linguistic Imperialism. Oxford: Oxford University Press.

17. Pinon, R. and Haydon, J. (2010) The benefits of the English language for individuals and societies: Quantitative indicators from Cameroon, Nigeria, Rwanda, Bangladesh and Pakistan. London, UK: The British Council.

18. Rwanda Education Board (2013) Renewed Drive to Improve the Quality of Education in Rwanda. Kigali: REB.

19. Rosendal, T. (2009) Linguistic markets in Rwanda: Language use in advertisements and on signs. Journal of Multilingual and Multicultural Development, 30(1), 19-39.

20. Samuelson, B.L. and Freedman, S. W. (2010) Language policy, multilingual education, and power in Rwanda. Language Policy, 9 (3), 199-215. Retrieved on 20January, 2015 from: http://www.berkeley.edu

21. Sayed, Y. et al. (2016) Engaging Teachers in Peacebuilding in Rwanda and South Africa. [Research Project Proposal]. Sussex: University of Sussex: Retrieved from: $\mathrm{http} / / \mathrm{www}$. sussex.ac.uk/education/cie/peacebuilding.

22. Sinclair, G.K. (2012) English in Rwanda: "Inevitability" meets obstacles on the ground. Toronto: University of Toronto. 
23. Steflja, I. (2012) The high cost and consequences of Rwanda's shift in language policy from French to English. Africa Portal Backgrounder No.30. Ontario, Canada: The Centre for International Governance Innovation. Retrieved on 21February, 2015, from: http://www.africaportal.org/articles/2012/05/31/ costs-and-consequencesrwanda\%E2\% $80 \% 99$ sshift-language-policy.

24. Tsuda, Y. (1997) Hegemony of English vs. Ecology of Language: Building Equality in International Communication. In World Englishes 2000. Honolulu: College of Languages, Linguistics and Literature.

25. Uwambayinema, E. (2013) Science Teachers' Challenges Implementing Rwanda's English as a Medium of Instruction Policy: A Case Study of Nyarugenge District Rural Secondary Schools. (Master's Thesis). California: California State University. 